\title{
Neural stem cell systems: physiological players or in vitro entities?
}

\section{Luciano Conti and Elena Cattaneo}

\begin{abstract}
Neural stem cells (NSCs) can be experimentally derived or induced from different sources, and the NSC systems generated so far are promising tools for basic research and biomedical applications. However, no direct and thorough comparison of their biological and molecular properties or of their physiological relevance and possible relationship to endogenous NSCs has yet been carried out. Here we review the available information on different NSC systems and compare their properties. A better understanding of these systems will be crucial to control NSC fate and functional integration following transplantation and to make NSCs suitable for regenerative efforts following injury or disease.
\end{abstract}

\section{Niche}

A multicellular

microenvironment supplying

the factors required to

maintain stem cell self-renewal

and to direct their

differentiation.

\section{Antigenic}

Pertaining to the expression of a specific marker or array of

markers, specific parts of which are recognized by antibodies.

\section{Neural plate}

The thickened stripe of ectoderm overlying the notochord in early vertebrate embryos which contains cells that will give rise to the nervous system during embryonic development

\section{Department of}

Pharmacological Sciences and Center for Stem Cell Research, University of Milan, Via Balzaretti 9, 20133

Milano, Italy.

e-mails:

luciano.conti@unimi.it; elena.cattaneo@unimi.it

doi:10.1038/nrn2761

Published online

28 January 2010
Neural stem cells (NSCs) are self-renewing multipotent populations present in the developing and adult mammalian $\mathrm{CNS}^{1,2}$. They generate the neurons and glia of the developing brain and also account for the limited regenerative potential of the adult brain. In vivo, NSCs exist in niches that support self-renewal and regulate the balance between symmetrical self-renewal and fate-committed asymmetrical division $^{3-6}$.

For nearly 20 years growth-factor-based protocols have been developed, leading to NSC expansion in both floating and adherent conditions ${ }^{7}$ and to a better understanding of the biological and molecular properties of NSCs. However, determining the best sources for the in vitro derivation of NSCs and optimizing protocols for stable, clonal proliferation are still central goals of stem cell research.

The in vitro synthetic milieu is thought to allow the expansion of bona fide NSCs - that is, cells that are operationally characterized by self-renewing and multipotential differentiation ${ }^{8}$, but the physiological relevance of these NSC models for the study of neural precursors during CNS development is still a subject of debate. Several studies indicate that some antigenic and biological properties might be maintained in NSC cultures even at late passages. However, other studies have shown that exposure to growth factors can deregulate the spatial identity and differentiation potential of neural precursors.

Here we compare the functional properties of NSCs grown in vitro with those of NSCs present in vivo and review the assays developed for their isolation and expansion. Finally, we discuss recent findings indicating that NSC identity might not accurately represent that of stem cells in vivo owing to the alteration of the cells' genetic and epigenetic status.

\section{NSCs in vivo and in vitro}

During brain development, predetermined programmes give rise to spatiotemporally different NSC populations, making the definition of the properties of NSCs challenging ${ }^{2}$. Although combined transcriptomic and proteomic approaches have improved our understanding of the molecular characteristics of NSCs and progenitor cells, such findings are far from definitive.

Neurogenesis in mammals begins with the induction of the neuroectoderm, which forms the neural plate (at embryonic day 7.5 (E7.5) in mice) and then folds to give rise to the neural tube (at E8.5 in mice). These structures are made up by a layer of so-called neuroepithelial progenitors (NEPs) ${ }^{9}$ (BOX 1), which are probably a complex and heterogeneous population. Progress in cell culture technologies has enabled researchers to induce the neuralization of mouse and human embryonic stem cells (ESCs) in vitro. During this neural differentiation, ESCs undergo progressive lineage restrictions similar to those observed in normal fetal development ${ }^{10,11}$, leading to the generation of a range of distinct neural precursor populations that can be used to study the molecular and cellular events that occur during stage-specific transitions between different populations ${ }^{12,13}$.

The identification of early stage-specific neural markers has allowed neural induction to be followed both in vivo and in vitro. SOX1 is one of the earliest known neural precursor markers in the mouse embryo $^{14}$. SOX1-positive neural progenitors with 'primordial' properties have been described ${ }^{15}$. These NEPs can be rapidly (within 24 hours) induced from mouse ESCs by exposing them to conditions that minimize any contact with extrinsic factors. This situation favours the 
Neural tube

The cylindrical structure formed by the fusion of neural

folds around the neural plate.

The brain and spinal cord

develop from the neural tube.

\section{Rosette}

Radial arrangements of

columnar cells that express

many of the proteins

expressed in neuroepithelial

are considered a

developmental signature of

neuroprogenitors in cultures

of differentiating ESCs. cells in the neural tube. They

appearance of a colony-forming leukaemia-inhibitory factor (LIF)-dependent 'primitive' NSC population with peculiar antigenic and developmental properties (FIG. 1; TABLES 1,2). Indeed, these primitive NSCs retain vestiges of ESC identity, such as OCT4 expression and a broad differentiation potential (observed in chimeric blastocyst experiments) ${ }^{15}$, suggesting that their neural commitment might be incomplete. Primitive NSCs are only a transient in vitro population as passaging switches them (the conversion being dependent on Notch signalling) to more committed neural precursors characterized by dependence on exogenous fibroblast growth factor 2 (FGF2), ceased expression of ESC markers and lost competence for chimaera formation. LIF-dependent NSCs with similar antigenic and functional properties can also be isolated from E5.5-7.5 mouse embryos ${ }^{16}$, indicating that they are not a peculiarity of the ESC neuralization process.

A fully neuralized early human ESC (hESC)-derived NEP population has recently been described ${ }^{17}$. Based on the evidence of a crucial role for SMAD signalling during vertebrate neural induction, these authors developed a dual-SMAD inhibition protocol for rapid (6 days) neuralization of hESCs, generating a population

\section{Box 1 | How many NSC or progenitor cell types are in the brain?}

Four main types of neural stem cell (NSC) or progenitor cell can be distinguished in the brain.

- Neuroepithelial progenitors (NEPs) are radially elongated and contact both the apical and the basal surfaces of the single-layered neuroepithelium. They divide at the ventricular zone (VZ), initially symmetrically to increase the pool of progenitor cells but later asymmetrically to generate a VZ progenitor and a daughter cell that migrates radially outward. NEPs are responsible for the first wave of neurogenesis in the neural tube, after which they give rise to both radial glia and basal progenitors.

- Radial glia (RG) originate from NEPs at the beginning of neurogenesis and are the main cell type in the developing brain, where they serve both as neural progenitors and as scaffolds for migrating newborn neurons. In contrast to NEPs, RG express astroglial markers such as GLAST (also known as SLC1A3), glial fibrillary acidic protein (GFAP) (only in humans and primates) and BLBP (also known as FABP7). RG undergo symmetrical proliferative or asymmetrical neurogenic divisions. Their differentiation potential is less broad than that of NEPs. Although subsets are tripotent, being able to generate neuronal, glial and oligodendroglial lineages, most seem to be bipotent or unipotent.

- Basal progenitors (BPs) are a distinct population of neurogenic precursors predominantly present in the subventricular zone (SVZ) in the developing telencephalon. They are generated at early stages of development by NEPs and at later stages by RG. BPs do not make contact with apical or basal surfaces of the neuroepithelium. Time-lapse imaging studies have revealed that most BPs undergo a single round of symmetrical division, generating one pair of neurons, but some are subjected to a second round of mitosis, generating two pairs of neurons. Therefore, $\mathrm{BPs}$ may be considered neurogenic transit-amplifying progenitors that specifically increase the production of neurons during restricted time periods. BPs lack expression of key transcriptional regulators that function in RG self-renewal, including PAX6 and SOX2, but they express TBR2, CUX1, CUX2 and SVET1.

- Adult progenitors are a population of multipotent neural cells mainly present in two specialized niches of the adult mammalian brain, the SVZ of the lateral ventricle wall and the subgranular zone of the dentate gyrus. They maintain neurogenesis and gliogenesis throughout adult life. They derive directly from RG that in the postnatal brain convert into astrocytic-like NSCs. Type B NSCs in the SVZ share many characteristics with astrocytes. These are in intimate contact with all other SVZ cell types, including the rapidly dividing transit-amplifying type $C$ cells and the lineage-committed migratory neuronal type A cells. of 'early' SOX1-, PAX6-, OTX2- and FOXG1-expressing NEPs (FIG. 1; TABLES 1,2). This protocol relies on strong inhibition of SMAD signalling by means of combined treatment of the hESCs with Noggin and the small molecule SB431542, the latter being a potent Lefty-Activin-Transforming growth factor- $\beta$ (TGF $\beta$ ) pathway inhibitor that blocks ALK receptor signalling. These early NEPs express some rosette-specific markers, although in a more primitive ES-like than polarized pattern. Interestingly, early hESC-derived NEPs are highly responsive to regionalization cues, allowing the efficient generation of neuronal subtypes relevant to that region (that is, tyrosine-hydroxylase-expressing neurons and Islet1- and HB9 (also known as MNX1)-positive motor neurons).

These early hESC-derived NEPs cannot be maintained in vitro as they spontaneously convert into a later-stage NEP population, which grows in rosette-like structures (named R-NSCs), with apical zonula occludens 1 (ZO1; a rosette-specific marker) expression and evidence of interkinetic nuclear migration ${ }^{18}$. R-NSCs can be maintained for some passages in vitro by sonic hedgehog $(\mathrm{SHH})$ and Notch receptor agonists and show an anterior FOXG1-positive NEP identity. Studies from the same group have shown that R-NSCs can also be directly isolated, by combining the detection of the expression of forebrain-surface-embryonic (Forse-1) epitope and $\mathrm{N}$-cadherin (also known as cadherin 2) cell sorting strategies, from neuralized mouse and human ESCs and from E8.25 anterior neural plate tissue exposed to $\mathrm{SHH}$ and Notch receptor agonists ${ }^{18}$. One of the most important properties of R-NSCs is their responsiveness to patterning signals, which is similar to that of early NEPs and enables them to adopt CNS or PNS fates. A similar phenomenon is observed during development, but only at the neural plate stage - not in neural precursors emerging after neural tube closure - supporting the idea that the R-NSCs represent NEPs of the neural plate stage. Owing to their intrinsic plasticity, R-NSCs would be an ideal NSC population for a range of basic and biomedical applications. Nevertheless, the effective and stable longterm maintenance of these cells in culture remains to be investigated. The overgrowth of R-NSCs that has been observed following transplantation into the adult CNS will need to be addressed before they can be used in cell therapy approaches ${ }^{18}$.

On exposure to commonly used mitogens (that is, FGF2 and epidermal growth factor (EGF)) R-NSCs are converted into a SOX1-negative radial glia (RG)-like population (named NSC ${ }^{\mathrm{FGF} / \mathrm{EGF}}$ ) with a more restricted differentiation potential ${ }^{18}$. Similar results have been shown to occur with a SOX1-positive transient NEP population obtained in vitro from a SOX1-enhanced green fluorescent protein (eGFP) reporter ESC line $\mathrm{e}^{11,19}$ by means of a serum-free monolayer protocol ${ }^{15}$. Unlike R-NSCs, this transient, not expandable SOX1-positive NEP population seems to acquire a posterior regional specification, possibly as a consequence of the caudalizing effect of retinoic acid in the culture medium, which prevents the development of rostral neuron subtypes (that is, glutamatergic telencephalic neurons) ${ }^{20}$. 


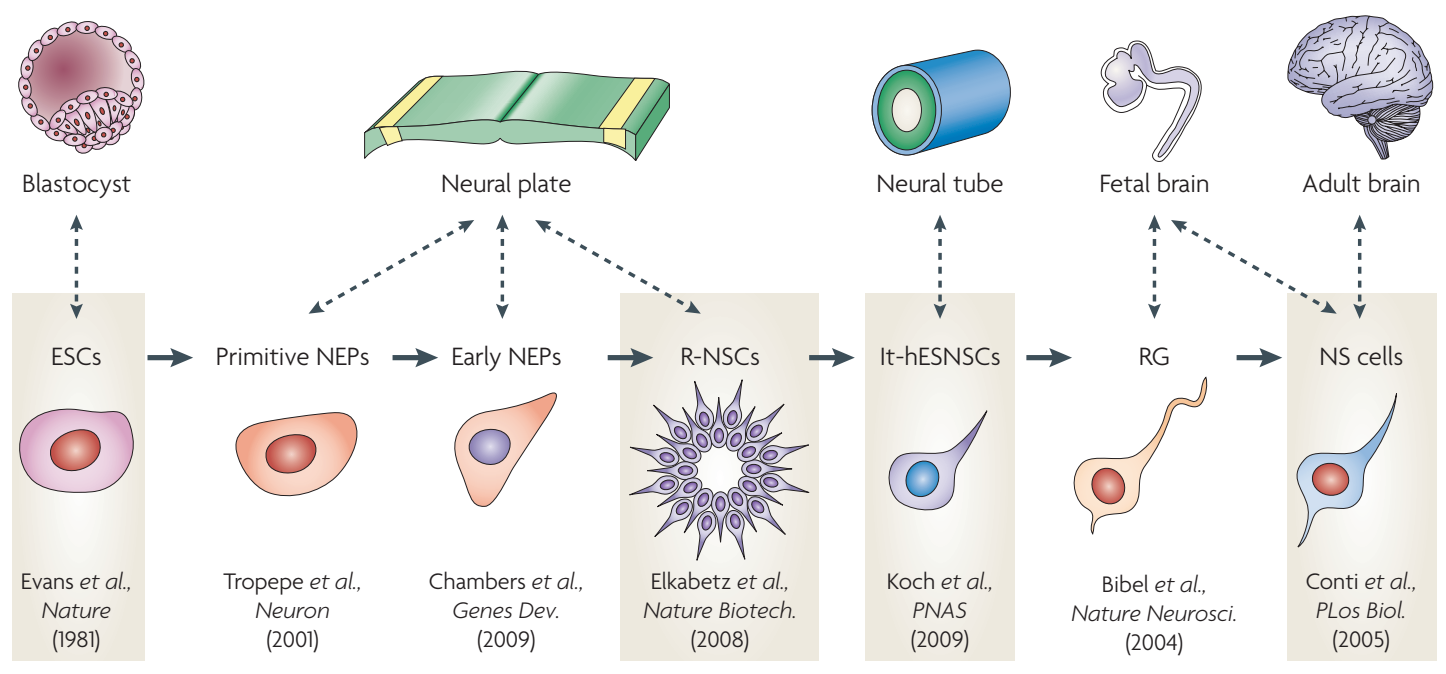

Figure 1 | Developmental links between the different NSC populations that can be isolated or generated in vitro. Shaded boxes indicate the neural stem cell (NSC) populations that can be obtained through mid-term or long-term expansion in vitro. The corresponding in vivo developmental stages and the reports that first described these populations are indicated. Induced pluripotent stem cells, generated by means of reprogramming, are thought to have the same developmental potential as embryonic stem cells (ESCs). Late NSCs have not been included as they have many similarities (in terms of growth factor requirements, antigenic profile and neuronal subtype specification) with NS cells, probably indicating that they represent an analogous population grown in different ways (monolayer and aggregation).

More recently, the generation of a pure population of SOX1-positive self-renewing hESC-derived NEPs (named 'lt-hESNSCs') has been described ${ }^{21}$ (FIG. 1; TABLES 1,2). These cells exhibit long-term self-renewal, clonogenicity and stable neurogenesis. Remarkably, they can be maintained for over 100 in vitro passages in the presence of FGF2 and EGF but still preserve some properties of the R-NSCs, such as rosette-like patterns, the expression of Forse-1, N-cadherin and ZO1 and responsiveness to instructive cues that promote the induction of distinct neuron subpopulations. Direct comparison of the gene expression profiles of R-NSCs and long-termexpanded lt-hESNSCs indicates that lt-hESNSCs partially retain rosette properties, possibly embodying an intermediate developmental stage between rosetteorganized NEPs and RG. Interestingly, lt-hESNSCs show a more posterior regional identity (a ventral anterior hindbrain identity code) than R-NSCs. This specific posterior identity could be a result of the in vitro expansion process as freshly isolated (passage 1 and 2) lt-hESNSCs show prominent expression of anterior markers such as OTX2 and FOXG1.

Later in development (E9.5 in mice), RG arise in the neural tube (BOX 1). Like NEPs, RG are a transient population in the developing brain that exhibit definite morphological hallmarks. Purification of RG from tissue has been efficiently achieved by means of fluorescenceactivated cell sorting (FACS) and transgenic mouse lines expressing the eGFP reporter under the control of RG-associated gene promoters (such as those of GLAST (also known as SLC1A3), BLBP (also known as FABP7) and human glial fibrillary acidic protein $(G F A P))^{22-24}$. In vivo, $\mathrm{RG}$ are characterized by lineage heterogeneity, with spatiotemporal diversity ${ }^{22,25-28}$. A similar heterogeneity in RG has also been appreciated in vitro, as distinct differentiation potentials have been observed depending on whether the RG were isolated at early or late developmental stages ${ }^{28,29}$. For example, focusing on forebrain development, $60-70 \%$ of RG isolated during the period of neurogenesis (from E14.5 to E16.5 in mice) differentiated into neurons, with a negligible proportion of bipotent RG generating neurons and other glia, including RG, astrocytes or oligodendrocytes ${ }^{24,30}$. At the end of neurogenesis (E18 in mice) neurogenic RG disappear ${ }^{31,32}$ and RG isolated at this stage are mostly gliogenic $\mathrm{c}^{33,34}$. Large numbers of RG are found in primary cell populations dissociated from E10.5-18.5 CNS tissue ${ }^{26}$, and these are a good source of stem cells that can be expanded and maintained in vitro ${ }^{26,35-37}$.

RG populations can be efficiently generated from ESCs using various differentiation protocols ${ }^{35,38-42}$, suggesting that the transition from a pluripotent ESC or multipotent NEP state towards neurons via an intermediate RG state may be a common step during the course of neuronal in vitro differentiation ${ }^{9,35,43}$. Indeed, transient populations of nearly pure PAX6-positive RG that matured into glutamatergic neurons, mimicking the process that occurs during cortical development, have been generated ${ }^{38,43}$ (FIG. 1; TABLES 1,2). Transplantation experiments in chicken embryos revealed that this PAX6-positive ESC-derived RG population is faterestricted and able to generate only a limited neuronal progeny ${ }^{44}$.

A remarkably different population of ESC-derived RG can be obtained by exposing SOX1-positive cells to EGF and FGF2, which leads to SOX1-negative, nestinpositive, BLBP-positive and PAX6-positive RG-like cells that can be expanded for over 100 passages in monolayer and at homogeneity ${ }^{35}$ (FIG. 1; TABLES 1,2). This conversion is dependent on Notch activity and on exposure to EGF 
and FGF2 (REFS 35,41). These self-renewing ESC-derived RG-like cells (named NS cells; see next section) maintain the marker signature of RG and full capacity for tripotential differentiation ${ }^{35,45}$. The difference between RG and RG-like NS cells is achieved solely by the in vitro differentiation protocol; the protocol that produces RG does not include any amplification step and causes fast proliferation and differentiation of ESCs into glutamatergic neurons $s^{43}$, whereas the protocol that produces NS cells depends on the addition of mitogens for continued proliferation as RG-like cells ${ }^{35}$.
Along with RG, another population of neural progenitors is represented by the basal progenitors (BPs) of the subventricular zone (SVZ) ${ }^{33,46,47}$ (BOX 1). BPs showing neuronal-restricted differentiation potential are generated both by NEPs and $\mathrm{RG}^{48,49}$. In vitro studies on BPs are very limited. BPs can be isolated from the forebrain of reporter mice based on the expression of TIS21 (also known as BTG2), a molecular marker of BPs that have switched from proliferative to neurogenic divisions ${ }^{50}$. A recent study has identified the production of BPs (in vitro) from a cortical RG subpopulation

\section{Table 1 | Comparative analysis of the characteristics and sources of derivation of iPSCs, ESCs and different NSC cultures}

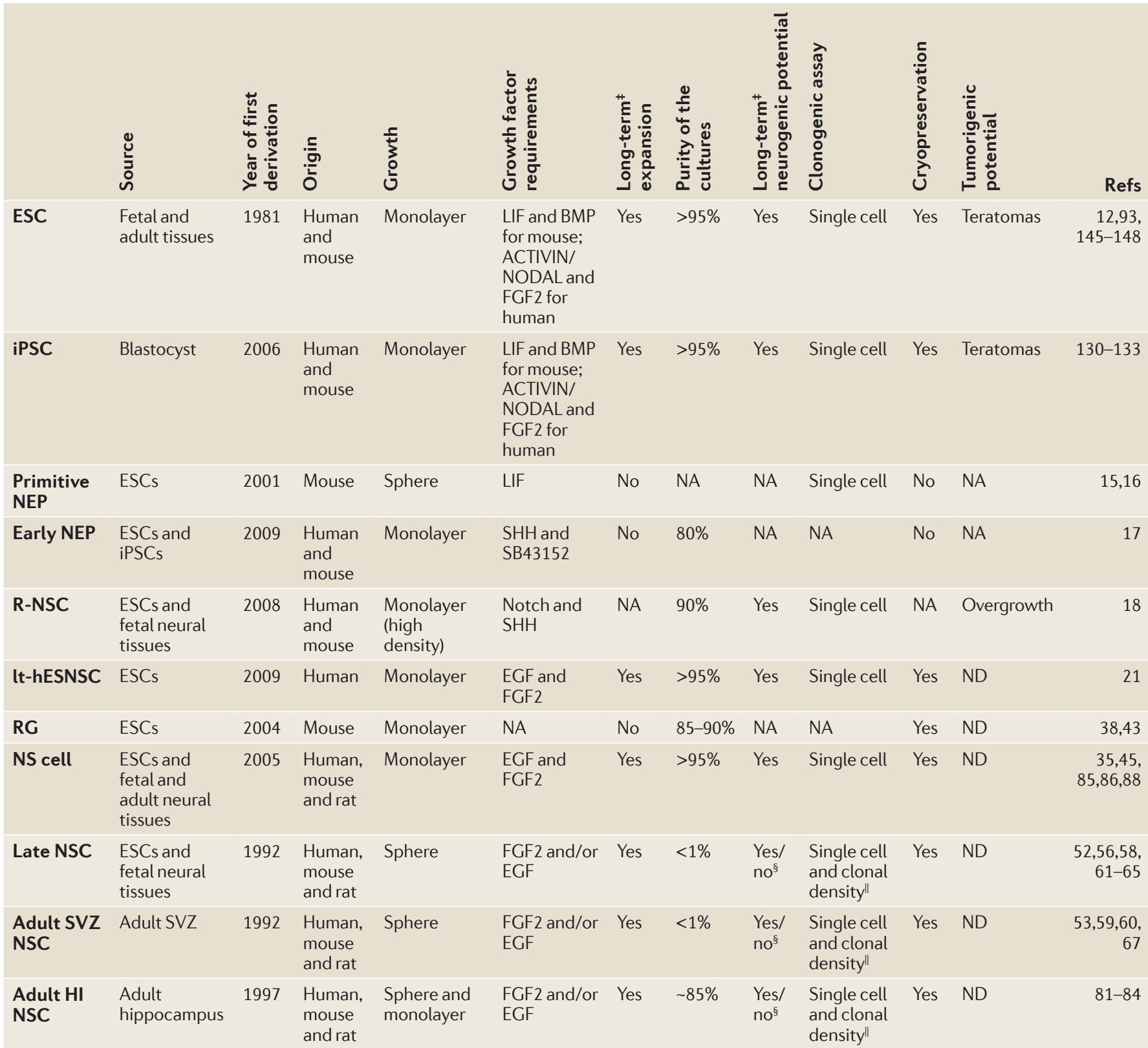

BMP, bone morphogenetic protein; EGF, epidermal growth factor; ESC, embryonic stem cell; FGF2, fibroblast growth factor 2; HI, hippocampus; iPSC, induced pluripotent stem cell; LIF, leukaemia-inhibitory factor; NA, not available; ND, not detected; NEP, neuroepithelial progenitor; NSC, neural stem cell; RG, radial glia; $\mathrm{SHH}$, sonic hedgehog; SVZ, subventricular zone. ${ }^{*} \mathrm{RG}$ cells described here are highly enriched mouse ESC-derived RG populations ${ }^{43}$; other RG derived from mouse $\mathrm{ESCs}^{40}$ and human $\mathrm{ESCs}^{42}$ have not been included in the table as the quantitative description of the cultures was limited. ${ }^{\prime}$ Long-term is defined as cultures that were expanded in vitro for at least 10 passages. ${ }^{\S} Y$ Yes/no indicates that the results of the studies considered are not consistent. "Clonal density refers to assays performed with cells plated at a density of 10-1,000 cells per $\mu$ l. 
isolated by means of sorting from eGFP reporter mice bearing the human GFAP promoter ${ }^{28}$. This RG population is characterized by a high immunoreactivity for prominin and can produce neurons only indirectly, through the production of BPs. Transient induction of neurogenic TBR2-positive BPs has also been described during the differentiation of ESCs to glutamatergic cortical neurons ${ }^{51}$.

In the adult mammalian brain, the presence of NSCs has been extensively investigated in two regions, the SVZ and the subgranular zone of the hippocampus, and their properties have been reviewed elsewhere ${ }^{1,60-62}$ (BOX 1).

\section{In vitro long-term propagation of NSCs}

Isolation of NSCs from their natural niche and their purification and expansion have been problematic, as the factors and cell contacts required to maintain these cells in their physiological state are poorly understood. EGF and FGF2 have been key players in the identification of cell culture conditions that sustain prolonged cell division of cells with NSC properties ${ }^{52-54}$. In this section we review the strategies developed for NSC isolation and expansion, and compare their power in terms of efficiency and long-term maintenance of the cells' 'genuine' molecular and biological properties.

\section{Table 2 | Comparative analysis of the developmental, molecular and neuronal differentiation properties of NSC systems}

\begin{tabular}{|c|c|c|c|c|c|c|c|c|c|}
\hline & 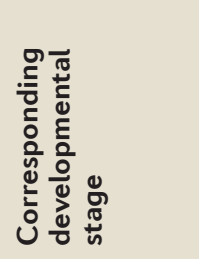 & 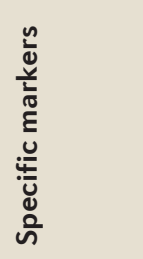 & 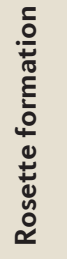 & 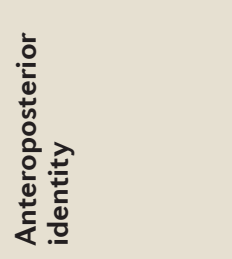 & 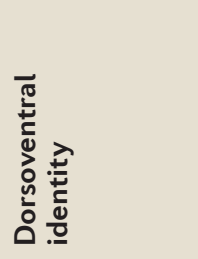 & 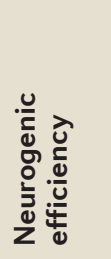 & 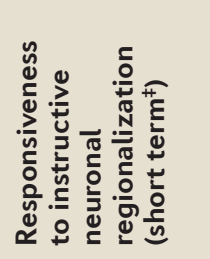 & 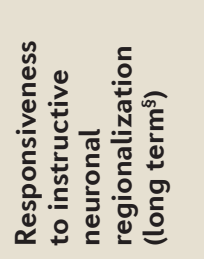 & Refs \\
\hline Early NEPs & $\begin{array}{l}\text { E7.5 }<\text { neural } \\
\text { plate }<\text { E8.25 }\end{array}$ & $\begin{array}{l}\text { Nestin, } \\
\text { SOX1 and } \\
\text { PAX6 }\end{array}$ & Yes & $\begin{array}{l}\text { Anterior (FOXG1 } \\
\text { and OTX2) }\end{array}$ & NA & NA & $\begin{array}{l}\text { Yes (tested: } \\
\text { TH, GABA and } \\
\text { motor neuron) }\end{array}$ & NA & 17 \\
\hline lt-hESNSCs & $\begin{array}{l}\text { E8.5 }<\text { neural } \\
\text { tube }<\text { E9.5 }\end{array}$ & $\begin{array}{l}\text { Nestin, } \\
\text { SOX1 and } \\
\text { PAX6 }\end{array}$ & Yes & $\begin{array}{l}\text { Anterior } \\
\text { hindbrain (EN1, } \\
\text { GBX2, HOXA2 } \\
\text { and HOXB2) }\end{array}$ & $\begin{array}{l}\text { Ventral } \\
\text { (NKX6.1 and } \\
\text { OLIG2); no } \\
\text { dorsal markers }\end{array}$ & $65-70 \%$ & $\begin{array}{l}\text { Yes (tested: } \\
\text { ventral TH } \\
\text { midbrain, } \\
\text { hindbrain } \\
\text { GABA } \\
\text { interneurons } \\
\text { and ventral } \\
\text { spinal cord } \\
\text { motor neurons) }\end{array}$ & $\begin{array}{l}\text { Yes (tested: } \\
\text { ventral TH } \\
\text { midbrain, } \\
\text { hindbrain } \\
\text { GABA } \\
\text { interneurons } \\
\text { and ventral } \\
\text { spinal cord } \\
\text { motor neurons) }\end{array}$ & 21 \\
\hline$R^{*}$ * & $\begin{array}{l}\text { E10.5< } \\
\text { forebrain }< \\
\text { E12.5 }\end{array}$ & $\begin{array}{l}\text { Nestin, } \\
\text { RC2, } \\
\text { SOX2, } \\
\text { BLBP, } \\
\text { GLAST } \\
\text { and PAX6 }\end{array}$ & No & Forebrain & Dorsal & $93.4 \%$ & NA & NA & 38,43 \\
\hline Late NSCs & $\begin{array}{l}\text { E9.5<CNS }< \\
\text { postnatal }\end{array}$ & $\begin{array}{l}\text { Nestin, } \\
\text { SOX2, } \\
\text { RC2 and } \\
\text { musashi }\end{array}$ & No & $\begin{array}{l}\text { Grossly } \\
\text { maintained } \\
\text { (depending on } \\
\text { the area and time } \\
\text { of derivation) }\end{array}$ & $\begin{array}{l}\text { Deregulated } \\
\text { along the } \\
\text { dorsoventral } \\
\text { axis }\end{array}$ & $10-25 \%$ & Yes & $\begin{array}{l}\text { Biased to } \\
\text { GABAergic }\end{array}$ & $\begin{array}{r}52,56,58, \\
61-65,95, \\
100,101, \\
106,107\end{array}$ \\
\hline
\end{tabular}

E, embryonic day; GABA, $\gamma$-aminobutyric acid; NA, not available; N-cad, N-cadherin (also known as cadherin 2); NEP, neuroepithelial progenitor; NSC, neural stem cell; RG, radial glia; TH, tyrosine hydroxylase . ${ }^{\star}$ RG described here are highly enriched mouse embryonic stem cell (ESC)-derived RG populations ${ }^{43}$; other RG derived from mouse $\mathrm{ESCs}^{40}$ and human $\mathrm{ESCs}^{42}$ are not included in the table as the quantitative description of the cultures was limited. ${ }^{\ddagger}$ Short term is defined as cultures that cannot be expanded in vitro for more than 3-5 passages. ${ }^{\S}$ Long term is defined as cultures that have been expanded in vitro for at least 10 passages. 
Neurosphere system. Neurospheres are free-floating aggregates of neural progenitors, each potentially derived from a single NSC ${ }^{52-54}$. Their generation relies on tissue microdissection (or dissociation of neuralized ESC or induced pluripotent stem cell (iPSC) cultures) followed by exposure to mitogens ${ }^{55}$. Commonly, mouse and rat neurospheres are harvested from neural tissue at E10.5-E18.5 or from the adult SVZ ${ }^{56-65}$. For their expansion, cells are plated in low-attachment tissue culture plastic dishes in serum-free media supplemented with EGF (10-20 ng per ml) and/or FGF2 (10-20 ng per $\mathrm{ml})^{66}$. In these conditions, most differentiating or differentiated cells are expected to die, whereas the NSCs respond to the mitogens, divide and form floating aggregates (primary neurospheres) that can be dissociated and re-plated to generate secondary neurospheres. This procedure can be repeated several times to expand an NSC population.

In the past few years, the identity of the neurosphereforming cell has been partially elucidated in the adult rodent SVZ. In the adult brain, both GFAP-positive type B cells and NG2 (also known as chondroitin sulfate proteoglycan 4)- and DLX2-positive type C cells located in the SVZ form neurospheres, but their long-term expansion has been thoroughly studied only for neurospheres derived from GFAP-positive cells ${ }^{67}$. The identity of the neurosphere-forming cell in the embryo is less well characterized. Most embryonic neurosphere cultures described in the literature often report only a superficial characterization in terms of NSC marker expression, hardly ever going beyond the expression of nestin. In these neurospheres, a variable proportion of cells also expresses other NSC markers, such as SOX2 and prominin, and markers of RG, such as RC2, GLAST and $\mathrm{BLBP})^{26}$. Interestingly, EGF receptor signalling is sufficient to regulate both the generation and the differentiation of morphologically, antigenically and functionally defined RG from mouse neurospheres upon adhesion ${ }^{68}$. This effect was also seen in human neurospheres exposed to a high EGF concentration (100 ng per $\mathrm{ml})^{36}$ and might indicate that the NSC components of the neurosphere have an RG identity.

Neurospheres have been used in vitro for defining, by extrapolation, the persistence and properties of NSCs in $v i v o^{69,70}$. The validity of this process may be questionable because of theoretical and technical intrinsic limitations of the assay, which is often erroneously performed ${ }^{66}$. In the original protocol for adult SVZ-derived spheres, 1,000 viable cells were plated per 35 -mm-diameter dish and the number of neurospheres was measured after 6-8 days ${ }^{53}$. However, we now know that unless a rigorous single-cell analysis is performed ${ }^{71}$, the number of spheres generated at this early stage cannot be regarded as a formal index of the number of NSCs in the tissue. Indeed, cell aggregation occurring in the extremely heterogeneous populations of cells that are present in the initial cultures might undermine the evaluation of single-cell multipotentiality ${ }^{66,72,73}$.

The cellular milieu of the neurosphere has been suggested to provide an in vitro counterpart to the in vivo neurogenic compartment, a microenvironment that is relevant for NSC maintenance, proliferation and differentiation. Although this concept of a neurosphere as an in vitro recapitulation of a niche-like structure has become extremely popular in the NSC field, it should be emphasized that a niche in vivo represents primarily a precise cell-specific microdomain with a spatial organization that helps regulate how stem cells participate in tissue generation, maintenance and repair ${ }^{74,75}$. The regulation of stem cell features in the niche requires both interactions between stem cells and interactions between stem cells and neighbouring differentiated cells, mediated by soluble and adhesion molecules and extracellular matrix components. In the rodent brain, the best characterized stem cell niche is the adult SVZ, where the different cell types are specifically organized with SVZ astrocytes (type B cells) located next to the ependymal layer and ensheathing chains of migrating young neurons $^{1}$. In this respect, neurospheres do not show any cellular organization in terms of cell types and distribution that may recapitulate the SVZ structure. Indeed, electron microscopy has shown that the neurosphere is composed of different cell types, mirroring the heterogeneity of the in vivo niche but with no spatial organization and no specific cell-cell interactions, which are typical of tissue stem cell niches ${ }^{76,77}$.

The heterogeneity of the neurospheres can be inherent in their three-dimensional structure (FIG. 2) as the different cells in the sphere can be exposed to suboptimal conditions; this is demonstrated by the tendency of neurospheres to generate differentiated cells in their core $^{74}$. Consequently, the interaction between differentiating cells and precursor cells may expose the NSCs to paracrine factors that promote differentiation.

Neurospheres show multipotency, although the maintenance of the neurogenic versus gliogenic potential gradually declines with in vitro passages (BOX 2). Different neuronal differentiation protocols based on mitogen removal and exposure to fetal bovine serum and/or to specific substrates and cytokines have been developed ${ }^{4,55,64,78,79}$, but none of them generates cells that are positive for the early neuronal marker $\beta 3$-tubulin at a proportion greater than $20 \%$. On the whole, this suggests that the neurosphere system is not particularly efficient in terms of neurogenic competence, but it can be useful for generating large numbers of neurons in vitro by means of cell sorting or genetic manipulation.

Monolayer systems. Early attempts to culture NSCs in monolayer conditions relied on plating them on polyornithine-, laminin- or fibronectin-coated dishes in serum-free media ${ }^{80}$, but only a few examples have successfully demonstrated the possibility of expanding NSC cultures in the long term.

One such example is represented by the progenitor cells from the adult rat hippocampus grown in monolayer in the presence of FGF2 (REF. 81). These cells show a variable degree of homogeneity for nestin and SOX2 expression, and asymmetrical cell division continuously replenishes the supply of multipotent progenitors. Similar cells have also been derived from the adult 
mouse $^{82}$ and human hippocampus ${ }^{83}$ and have been shown to undergo some degree of neuronal differentiation in vitro ${ }^{81,84}$.

More recently, other strategies for the derivation and stable long-term propagation of NSC lines from different sources of rodent ${ }^{35,85}$ and human ${ }^{86}$ origin have been described. According to these procedures, neural precursors can be competently expanded as adherent, clonal, uniform NS cell lines by exposure to EGF and FGF2 (REFS 18,21,35). Under these conditions cells divide symmetrically, retaining their tripotential differentiation capacity, indicating that monolayer culture systems can maintain almost pure NSC populations ${ }^{35}$, with a negligible differentiated component. The key aspect of the NS cell culture system lies in the combination of EGF and FGF2 used and the focus on cells that grow adherently. The continuous provision of EGF together with FGF2 seems to be essential for the derivation and propagation of these monolayer-growing NS cells,
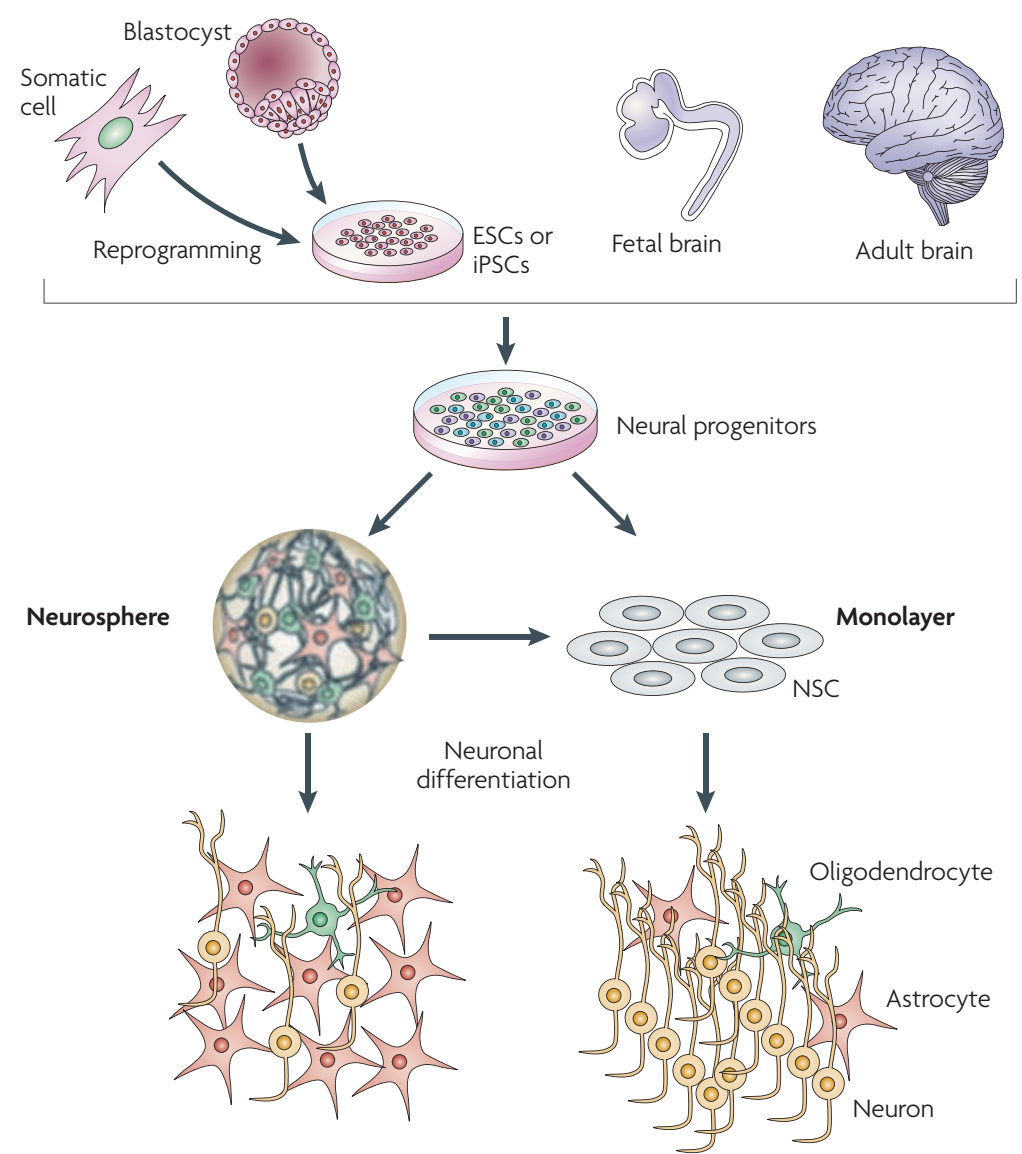

Figure 2 | Sources of neurospheres and monolayer NSCs and results of differentiation. Neurospheres and monolayer neural stem cell (NSC) lines can be generated from embryonic stem cells (ESCs) (derived from the inner cell mass of blastocysts), from induced pluripotent stem cells (iPSCs) (derived from reprogrammed somatic cells) and from the germinative areas of the fetal and adult brain. Neurospheres and cells grown in monolayers can be considered tripotent as they can give rise to neurons, astrocytes and oligodendrocytes. The different cellular compositions of the neurosphere (mixed, with only a fraction of the cells exhibiting NSC properties) and NSC monolayer culture (homogeneous composition) systems results in low and high neurogenic potential, respectively. whether sourced from ESCs or fetal or adult brain ${ }^{81}$. This NS cell population shows a remarkable antigenic similarity to forebrain neurogenic $\mathrm{RG}^{35,85}$. These properties are also manifested by the $\mathrm{NSC}^{\mathrm{EGF} / \mathrm{FGF}}$ population directly derived from R-NSCs exposed to EGF and FGF2 (REF. 18). The fact that NS cells can also be established from long-term expanded neurospheres indicates that RG-like cells might be the NSC fraction in neurospheres and that monolayer growth conditions may allow their enrichment and subsequent expansion ${ }^{35}$.

hESC-derived lt-hESNSCs can also be maintained for a long time in monolayer conditions. Unlike NS cells and NSC ${ }^{\text {EGF/FGF }}$ cells, lt-hESNSCs show sustained SOX1 expression and partially retain the capacity to respond to patterning cues. Interestingly, lt-hESNSCs exhibit rosette-like patterns even after extensive passaging in vitro. Direct gene expression comparison between rosette-type R-NSCs and lt-hESNSCs showed that many rosette-specific genes (for example, $D A C H 1$ and PLZF (also known as ZBTB16)) are common to the two cell types, whereas other genes described in the rosette stage are undetectable in lt-hESNSCs. This indicates that lt-hESNSCs might be expandable with FGF2 and EGF, retaining intermediate properties between the R-NSCs and the RG-like NS and NSC ${ }^{\mathrm{EGF} / \mathrm{FGF}}$ populations. It can be speculated that some rosette-stage properties can be maintained in lt-hESNSCs thanks to the strong expression of the Notch-downstream genes HES5 and HEY1, suggesting that this pathway, which is essential for R-NSC maintenance, might be constitutively active during the proliferation of lt-hESNSCs. Successful maintenance of lt-hESNSCs also depends on the specific composition of the cell culture medium. In particular, a low concentration of B27 supplement seems to be essential, as media without or with high concentrations of B27 promote spontaneous differentiation and senescence as well as a reduced responsiveness to instructive factors. Notably, media used for both NS cells and NSC ${ }^{\mathrm{EGF} / \mathrm{FGF}}$ cell growth do not contain B27.

Interestingly, cells in these EGF- and FGF2-dependent monolayers retain multipotentiality and neurogenic efficiency after prolonged in vitro expansion and show a high competence to efficiently originate antigenically and electrophysiologically mature neurons on exposure to optimized differentiating conditions ${ }^{21,35,87,88}$ (FIG. 2). This capacity can probably be interpreted as a consequence of the homogeneity of the starting population.

The fact that nearly homogeneous cell populations with NSC features have been grown for sustained periods under adherent conditions indicates that the NSC niche is dispensable for in vitro NSC propagation. The artificial two-dimensional structure ensured by monolayeradherent cultures seems to prevent lineage restriction and minimize spontaneous differentiation, favouring niche-independent, symmetrical self-renewal and expansion of rather homogeneous cell populations.

Mechanisms for the establishment of NSC systems In vitro assays based on neurospheres or adherent colony formation are regularly regarded as a means to infer in vivo NSC frequency and properties ${ }^{64,89-92}$. 


\section{Box 2 | Criteria defining the value of long-term self-renewing NSC systems}

\section{Efficiency of propagation}

Efficiency of propagation is directly correlated to the composition of the system ${ }^{137}$. In neurospheres, the neural stem cell (NSC) content is variable and depends on the stage of the culture - it is high soon after the dissociation and replating but declines progressively with subsequent subculturing ${ }^{64,138}$. Conversely, NSCs grown in monolayers show a higher degree of homogeneity, suggesting that these conditions favour symmetrical cell division over long time periods ${ }^{35,85,86}$.

\section{Clonality}

Clonality is fundamental for the retrospective identification of the NSC identity of a cell in vitro. In the strict sense of the term, a cell clone should derive from a single isolated cell in a separate well. This has been described for both monolayer cultures $^{64,89,90}$ and neurospheres. However, this is often achieved by plating at the so-called clonal density - that is, $10-1,000$ cells per $\mu$ l. Thus, what should be a clonal density is often represented by a bulk culture, hampering the initial scope of the clonal assay. Also, aggregation between separate neurospheres has been reported, resulting in the lack of clonality in any one sphere ${ }^{66,72,73}$.

\section{Karyotypic stability following extensive proliferation}

The long-term stability of mouse NSCs expanded in vitro has been poorly documented ${ }^{139-142}$. Some studies support the observation that after long-term culture in vitro NSCs are transformed into malignant cells ${ }^{142}$. However, one study reported a normal karyotype in neurosphere cultures at passage 70 (REF. 140). Nevertheless, to circumvent this limitation, it is common to avoid using neurospheres beyond the tenth passage. Abnormalities in mouse cells that have been cultured for a long time are common and have also been reported in monolayers of NS cells ${ }^{88}$ and hippocampal cell lines ${ }^{81}$. NSC cultures of human origin grown in monolayers seem to retain a normal diploid karyotype after long-term expansion ${ }^{21,86}$.

\section{Retention of neuropotency}

Several studies indicate that gliogenesis is more prevalent in neurospheres that have undergone long-term expansion. It is thought that this switch from neurogenic to gliogenic potential is reminiscent of events that occur during development, suggesting that intrinsic cellular programmes are preserved in vitro. The gradual loss of neurogenic potential has often been reported for neurospheres. Conversely, NS cells, NSCEGF/FGF and lt-hESNSC monolayer systems retain the capability to produce a large proportion of neurons after prolonged expansion (TABLE 2), suggesting that maintenance in a symmetrical division state can preserve the cells' original neurogenic potential ${ }^{88}$. Alternatively, they can correspond to populations of neurogenic cells present at specific developmental stages ${ }^{143,144}$. It is of note that maintenance of a stable neurogenic potential does not impede prompt responses to gliogenic signals.

\section{Clonal density}

The density of cells (number of cells per $\mu$ l) that should allow

formation of single-cell clones. Rigorously, clonality is assured solely by plating a single cell per well, thus allowing the investigation of properties of single cells. This step is

essential for formal demonstration of self-renewal and potency
However, the actual correlation between in vitro stem cell lines and in vivo progenitors is uncertain, and there is increasing concern about the physiological relevance of studying stem cells in vitro. For example, it is unclear whether these cells represent a subpopulation of authentic homologues found in vivo or whether they are the result of 'forced' reprogramming in vitro. In the developing mammalian brain, both transplantation and in vivo fate mapping experiments have so far failed to provide definitive proof of the presence of self-renewing NSCs rather than progenitor cells ${ }^{2}$. In most tissues and organs, the founder cells that are present during embryogenesis either do not endure or switch to a relatively quiescent state following the conclusion of development. This suggests that the NSC state might represent an in vitro condition possibly induced by the experimental set-up. ESCs, for example, have a close molecular relationship to inner cell mass founder cells of the blastocyst ${ }^{12,93}$ and express genes that are not typically detectable in the inner cell mass, which may be crucial for establishing and maintaining ESCs in vitro.
EGF and FGF2, the growth factors that are most frequently used for preserving NSCs in vitro, might alter the transcriptional and cellular phenotype. Many genes can be directly induced in neural progenitors by in vitro exposure to FGF2 or $\mathrm{EGF}^{94}$, suggesting that these growth factors might exert a crucial role in the creation of NSC lines in vitro. In fact, EGF has been reported to downregulate expression of DLX2 in homogeneous NS cell lines and NSC $\mathrm{EGF}^{\mathrm{EFGF}}$ cultures $^{85}$ and in transitamplifying cells of the $\mathrm{SVZ}^{67}$, promoting their conversion into RG-like NSCs in vitro. Also, fetal progenitors, when exposed to FGF2 in vitro, rapidly activate the expression of EGF receptor (also known as ERBB1) 57,58 and OLIG2 (REF. 95), a basic helix-loop-helix transcription factor associated with the oligodendrocyte lineage ${ }^{96}$ and ventral CNS identity. Under expansion conditions with high levels of EGF and FGF2, induction of OLIG2 is required for the proliferation and self-renewal of neurosphere cells ${ }^{97}$.

The importance of FGF2-mediated OLIG2 induction for the self-renewal and proliferation of NSCs has been demonstrated in neurosphere systems, although with the caveat indicated above ${ }^{66}$. Indeed, similarly to the effect of deletion of BMI1 (a polycomb gene required for the self-renewal of stem cells from diverse tissues) ${ }^{98}$, interference with OLIG2 severely reduces the number and size of neurospheres ${ }^{97}$. Besides the FGF2-mediated induction of OLIG2 (REFS 99-102), short-term exposure to FGF2 induces the expression of a broad set of genes in primary neural precursors. Among these are $C D 44, A D A M 12$, CX3CL1, CDH20, KITLG, FZD9, GLAST, OLIG1 and VAV3 (REF. 103). Many of them are likely to have substantial roles in determining the phenotype of the cells. For example, upregulation of proto-oncogenes, such as the RhoGEF family member $V A V 3$, could alter cell adhesion $^{104}$ and division ${ }^{105}$. Interestingly, induction of some of these genes (for example CD44 and VAV3) occurs rapidly (within 5 hours of FGF2 exposure) ${ }^{103}$. Thus, the speed and nature of the gene expression changes suggest that FGF2 action does not mediate a standard developmental progression but rather an acute transcriptional resetting.

With respect to regional identity, there are data showing profound differences between gene expression patterns in vitro and in primary precursors in vivo, which could lead to the emergence of a mixed regional identity and limited neuronal differentiation ${ }^{95,101,106,107}$. For example, neurospheres from the spinal cord have been shown to undergo upregulation of OLIG2 and downregulation of the dorsal spinal cord transcription factors PAX3 and PAX7 (REF. 100). OLIG2 and MASH1 (also known as ASCL1) are also induced in E14 cortex precursors grown in the short or long term as neurospheres ${ }^{101}$. With some exceptions ${ }^{86}$, a similar deregulation of the regional patterning is evident in the adherent NS cell cultures ${ }^{35,85,86}$. $\mathrm{RG}$ in vivo are heterogeneous in terms of their transcription factor expression profile, a feature that is expected to confer positional signals ${ }^{108}$. However, homogeneous co-expression of PAX6, OLIG2 and EMX2 is present in virtually all NS cell cultures derived from ESCs, fetal forebrain or adult SVZ, but these cultures are negative for some ventral markers such as LHX6 (REFS 35,85). 


\section{Box 3 | Comparison of the main characteristics of NSCs in vivo and in vitro}

-In vivo the presence of a niche stringently controls stem cell activity. In vitro neural stem cells (NSCs) can divide and differentiate in the absence of a niche.

-Asymmetrical cell division predominates in vivo; asymmetrical and symmetrical cell division are both observed in vitro.

- NSC identity in vivo evolves through developmental stages. In vitro this temporal evolution is partially recapitulated during embryonic stem cell neuralization processes. NSCs that have undergone long-term expansion mainly have a single radial glia-like identity.

- In vivo a clear separation between NSCs and transient amplifying progenitors can be drawn; transient amplifying progenitors can acquire an NSC identity in vitro.

- Precise region-specific NSC populations are present during brain development. Specific NSC positional identities can be imposed in in vitro neuralized ESCs. In vitro NSCs that have undergone long-term expansion tend to lose the codes of transcription factors that determine positional identity.

- NSCs in vivo generate various differentiated neuronal subtypes. NSCs that have undergone long-term in vitro expansion can give rise to limited assortments of specialized neuronal progeny.

-Authentic neuronal functional phenotypes are acquired in vivo. Only partial functional maturation can be achieved in vitro. be best viewed as an environment that represses regional or cell type-specific differentiation and promotes high rates of proliferation. Recent studies support the idea that the NSC cell cycle may influence cell fate. In fact, it was shown that cell cycle lengthening caused cortical progenitors to undergo differentiative divisions, whereas cell cycle shortening resulted in more self-renewing divisions ${ }^{110}$. Numerous cell cycle-specific genes have been identified as important regulators of NSC proliferation in vivo and many of them are important for the establishment and maintenance of NSCs in vitro ${ }^{111-114}$ (these include BMI1 (REFS 98,115-117), CDKN1A (also known as p21, WAF1 and CIP1) ${ }^{118}$ and nucleostemin (also known as $G N L 3)^{119,120}$ ). Interestingly, some of these genes are under the direct regulation of FGF2-induced transcription factors, such as OLIG2, which may mediate proliferation by regulating CDKN1A levels ${ }^{97}$.

Derivation of NSC lines could hence be interpreted as a fate reprogramming assay rather than a direct measure of the number and properties of endogenous NSCs. In this respect, it has been shown that oligodendrocyte precursor cells can be converted to a tripotent state in vitro through bone morphogenetic protein- and FGF-induced chromatin modifications ${ }^{121-123}$. Similarly, in the adult brain only transit-amplifying type C cells, not GFAPimmunoreactive type $\mathrm{B}$ cells, respond to growth factors and can be expanded in vitro as an NSC population ${ }^{67}$.

The actual criteria that define an NSC might have to be reconsidered in the light of recent findings, such as the observation that epigenetic modifications may permit the generation of cells with some of the antigenic properties of neural-like cells and neurons from non-neural lineages ${ }^{124-126}$, although stringent biological, molecular and functional analyses indicated that these cells cannot be considered true NSCs and neurons ${ }^{127}$. The recent advent of iPSCs has questioned our notion of what constitutes a terminally differentiated somatic cell $^{128-132}$. The fact that methyltransferase and histone deacetylase inhibitors greatly enhance iPSC generation points to chromatin modification being a crucial determinant of cellular reprogramming ${ }^{133}$.

Epigenetic regulation of transcription as a means of reprogramming cell fate is attracting a lot of attention ${ }^{134}$. DNA methylation plays a key part in the determination of neuronal or glial fate in NSCs ${ }^{135}$, and methylation status, which can be modulated by FGF2, has been shown to be closely linked to the multipotency of NSCs both in vivo and in vitro ${ }^{136}$.

Together, these findings suggest that NSCs in vitro are distinct from neural progenitors in vivo (for a concise comparison of their properties, see BOX 3) and that the self-renewal and multipotency demonstrated by NSCs in vitro might not be an accurate representation of stem cells in vivo, owing to the exposure to growth factors acting at both the transcriptional and the epigenetic levels. Although this NSC state might be a synthetic stem cell state created in vitro, a similar phenotype may also emerge in pathophysiological conditions. In this case, studying NSCs in vitro may contribute to our understanding of these conditions and lead to potential biomedical applications. 


\section{Conclusions and future directions}

Our knowledge of neural progenitor identity and properties during development has been revolutionized by the ability to isolate and expand NSCs in vitro. In this article we have reviewed the current and most commonly used sources of NSCs and in vitro methodologies to isolate, expand and functionally characterize NSC populations (for a summary see TABLE 1). The real identity of and the potential lineage relationships between diverse types of stem or precursor cells isolated and cultured in vitro by these different methodologies are still being investigated.

Nonetheless, in vitro settings necessarily result in a disruption of the three-dimensional tissue structure, loss of specific cell-cell contacts and modification of the extracellular environment and intracellular signalling cascades, possibly altering the biological and molecular properties responsible for the acquisition of stem cell features.

Given that NSC biology holds tremendous potential for therapy, it will be crucial to be able to manipulate the properties of NSCs and to impose particular developmental programmes in vitro. Although it remains to be determined whether any particular human CNS disease will benefit from NSC transplantation, it is also becoming clear that the regenerative capacity and plasticity of the brain requires not only NSC competence but also the ability of other cells to participate in the repair process. Careful planning and extensive animal testing will be required before clinical studies with NSCs can be considered, and even then these trials should be performed in concert with other traditional therapies that aim to ameliorate degeneration and promote neuroprotection.

Emerging knowledge of the molecular biology and genetics of NSCs and their bioactive products, as well as of the injured microenvironment, will refine our judgment of when and how to use NSCs. In the meantime, several steps are required to move the field towards the ultimate goal. We should better standardize methods and protocols of isolation and culture of NSCs of human origin, improve the evaluation of the clinical efficacy of NSC transplants in adequate animal models, study the molecular mechanisms of the limitations of intrinsic brain repair, learn to promote the long-term survival of these cells by creating a more permissive environment (and niche) in the diseased brain and incorporate into future stem cell transplantation trials more detailed knowledge of the specific disease mechanisms.

Although current NSC systems are not perfect, propagation close to homogeneity has set the stage for the next round of discoveries. One can anticipate that a rigorous assessment of the functional features of NSC populations isolated and propagated by means of different cell culture systems, combined with new knowledge about cellular reprogramming, will allow us to exploit the advantages offered by these different systems to the full.
1. Chojnacki, A. K., Mak, G. K. \& Weiss, S. Identity crisis for adult periventricular neural stem cells: subventricular zone astrocytes, ependymal cells or both? Nature Rev. Neurosci. 10, 153-163 (2009).

2. Temple, S. The development of neural stem cells. Nature 414, 112-117 (2001).

3. Alvarez-Buylla, A. \& Lim, D. A. For the long run: maintaining germinal niches in the adult brain. Neuron 41, 683-686 (2004).

4. Garcion, E., Halilagic, A., Faissner, A. \& ffrenchConstant, C. Generation of an environmental niche for neural stem cell development by the extracellular matrix molecule tenascin C. Development 131 , 3423-3432 (2004).

5. Shen, Q. et al. Endothelial cells stimulate self-renewal and expand neurogenesis of neural stem cells. Science 304, 1338-1340 (2004).

This study provided data suggesting the presence of an endothelial niche that regulates NSC activity in the brain.

6. Shen, Q. et al. Adult SVZ stem cells lie in a vascular niche: a quantitative analysis of niche cell-cell interactions. Cell Stem Cell 3, 289-300 (2008).

7. Kokovay, E., Shen, Q. \& Temple, S. The incredible elastic brain: how neural stem cells expand our minds. Neuron 60, 420-429 (2008).

8. Gage, F. H. Mammalian neural stem cells. Science 287, 1433-1438 (2000)

9. Gotz, M. \& Huttner, W. B. The cell biology of neurogenesis. Nature Rev. Mol. Cell Biol. 6, 777-788 (2005).

10. Pankratz, M. T. et al. Directed neural differentiation of human embryonic stem cells via an obligated primitive anterior stage. Stem Cells 25, 1511-1520 (2007).

11. Ying, Q. L., Stavridis, M., Griffiths, D., Li, M. \& Smith, A. Conversion of embryonic stem cells into neuroectodermal precursors in adherent monoculture. Nature Biotech. 21, 183-186 (2003).

12. Nishikawa, S., Jakt, L. M. \& Era, T. Embryonic stemcell culture as a tool for developmental cell biology. Nature Rev. Mol. Cell Biol. 8, 502-507 (2007).

13. Zhang, S. C. Neural subtype specification from embryonic stem cells. Brain Pathol. 16, 132-142 (2006).
14. Pevny, L. H., Sockanathan, S., Placzek, M. \& LovellBadge, R. A role for SOX1 in neural determination. Development 125, 1967-1978 (1998).

15. Tropepe, V. et al. Direct neural fate specification from embryonic stem cells: a primitive mammalian neural stem cell stage acquired through a default mechanism. Neuron 30, 65-78 (2001).

This study described the rapid induction of "primitive" LIF-responsive transient neuroepithelial cells from mouse ESCs exposed to conditions that minimize the presence of extrinsic factors.

16. Smukler, S. R., Runciman, S. B., Xu, S. \& van der Kooy, D. Embryonic stem cells assume a primitive neural stem cell fate in the absence of extrinsic influences. J. Cell Biol. 172, 79-90 (2006)

17. Chambers, S. M. et al. Highly efficient neural conversion of human ES and iPS cells by dual inhibition of SMAD signaling. Nature Biotech. 27 275-280 (2009).

This paper described the rapid generation of early neuroepithelial cells from hESCs by means of a strong inhibition of SMAD signalling. These early neuroepithelial cells constitute a transient pre-rosette population.

18. Elkabetz, Y. et al. Human ES cell-derived neural rosettes reveal a functionally distinct early neural stem cell stage. Genes Dev. 22, 152-165 (2008). This study was the first to demonstrate that hESC-derived neural rosettes can be maintained for some passages in vitro by $\mathrm{SHH}$ and Notch receptor agonists. In the same paper it was also shown that this cell population can also be directly isolated, by means of the combination of Forse- 1 and $\mathrm{N}$-cadherin cell-sorting strategies, from anterior neural plate-stage tissue.

19. Suter, D. M., Tirefort, D., Julien, S. \& Krause, K. H. A Sox 1 to Pax6 switch drives neuroectoderm to radial glia progression during differentiation of mouse embryonic stem cells. Stem Cells 27, 49-58 (2008).

20. Glaser, T. \& Brustle, O. Retinoic acid induction of ES-cell-derived neurons: the radial glia connection. Trends Neurosci. 28, 397-400 (2005).

21. Koch, P., Opitz, T., Steinbeck, J. A., Ladewig, J. \& Brustle, O. A rosette-type, self-renewing human ES cell-derived neural stem cell with potential for in vitro instruction and synaptic integration. Proc. Natl Acad. Sci. USA 106, 3225-3230 (2009). This paper demonstrated that a well-defined hESC-derived population of post-rosette-stage neuroepithelial cells can retain some developmental plasticity following long-term propagation in the presence of EGF and FGF2.

22. Anthony, T. E. \& Heintz, N. Genetic lineage tracing defines distinct neurogenic and gliogenic stages of ventral telencephalic radial glial development. Neural Dev. 3, 30 (2008).

23. Anthony, T. E., Klein, C., Fishell, G. \& Heintz, N. Radial glia serve as neuronal progenitors in all regions of the central nervous system. Neuron 41, 881-890 (2004).

24. Malatesta, P., Hartfuss, E. \& Gotz, M. Isolation of radial glial cells by fluorescent-activated cell sorting reveals a neuronal lineage. Development 127 , 5253-5263 (2000).

25. Gotz, M., Stoykova, A. \& Gruss, P. Pax6 controls radial glia differentiation in the cerebral cortex. Neuron $\mathbf{2 1}$, 1031-1044 (1998).

26. Hartfuss, E., Galli, R., Heins, N. \& Gotz, M. Characterization of CNS precursor subtypes and radial glia. Dev. Biol. 229, 15-30 (2001).

27. Ogawa, Y. et al. Gliogenic radial glial cells show heterogeneity in the developing mouse spinal cord Dev. Neurosci. 27, 364-377 (2005).

28. Pinto, L. et al. Prospective isolation of functionally distinct radial glial subtypes--lineage and transcriptome analysis. Mol. Cell. Neurosci. 38 , 15-42 (2008).

29. Li, H., Babiarz, J., Woodbury, J., Kane-Goldsmith, N. \& Grumet, M. Spatiotemporal heterogeneity of CNS radial glial cells and their transition to restricted precursors. Dev. Biol. 271, 225-238 (2004).

30. Malatesta, P. et al. Neuronal or glial progeny: regional differences in radial glia fate. Neuron 37, 751-764 (2003).

31. Miyata, T., Kawaguchi, A., Okano, H. \& Ogawa, M. Asymmetric inheritance of radial glial fibers by cortical neurons. Neuron 31, 727-741 (2001).

32. Shen, Q. et al. The timing of cortical neurogenesis is encoded within lineages of individual progenitor cells. Nature Neurosci. 9, 743-751 (2006). 
33. Noctor, S. C., Martinez-Cerdeno, V., Ivic, L. \& Kriegstein, A. R. Cortical neurons arise in symmetric and asymmetric division zones and migrate through specific phases. Nature Neurosci. 7, 136-144 (2004).

34. Schmid, R. S. et al. Neuregulin 1-erbB2 signaling is required for the establishment of radial glia and their transformation into astrocytes in cerebral cortex. Proc. Natl Acad. Sci. USA 100, 4251-4256 (2003).

35. Conti, L. et al. Niche-independent symmetrical selfrenewal of a mammalian tissue stem cell. PLOS Biol. 3 e283 (2005)

The first evidence that it is possible to derive pure NSC lines that exhibit features of neurogenic RG progenitors.

36. Nelson, A. D., Suzuki, M. $\&$ Svendsen, C. N. A high concentration of epidermal growth factor increases th growth and survival of neurogenic radial glial cells within human neurosphere cultures. Stem Cells 26 , 348-355 (2008)

37. Yoon, K. et al. Fibroblast growth factor receptor signaling promotes radial glial identity and interacts with Notch 1 signaling in telencephalic progenitors. J. Neurosci. 24, 9497-9506 (2004).

38. Bibel, M., Richter, J., Lacroix, E. \& Barde, Y. A. Generation of a defined and uniform population of CNS progenitors and neurons from mouse embryonic stem cells. Nature Protoc. 2, 1034-1043 (2007).

39. Bouhon, I. A., Joannides, A., Kato, H., Chandran, S. \& Allen, N. D. Embryonic stem cell-derived neural progenitors display temporal restriction to neural patterning. Stem Cells 24, 1908-1913 (2006).

40. Liour, S. S. et al. Further characterization of embryonic stem cell-derived radial glial cells. Glia 53, 43-56 (2006).

41. Lowell, S., Benchoua, A., Heavey, B. \& Smith, A. G. Notch promotes neural lineage entry by pluripoten embryonic stem cells. PLoS Biol. 4, e121 (2006).

42. Nat, R. et al. Neurogenic neuroepithelial and radial glial cells generated from six human embryonic stem cell lines in serum-free suspension and adherent cultures. Glia 55, 385-399 (2007)

43. Bibel, M. et al. Differentiation of mouse embryonic stem cells into a defined neuronal lineage. Nature Neurosci. 7, 1003-1009 (2004). This report described the efficient generation of highly enriched RG populations during ES neurona differentiation.

44. Plachta, N., Bibel, M., Tucker, K. L. \& Barde, Y. A Developmental potential of defined neural progenitors derived from mouse embryonic stem cells. Development 131, 5449-5456 (2004).

45. Glaser, T., Pollard, S. M., Smith, A. \& Brustle, O. Tripotential differentiation of adherently expandable neural stem (NS) cells. PLOS ONE 2, e298 (2007)

46. Haubensak, W., Attardo, A., Denk, W. \& Huttner, W. B. Neurons arise in the basal neuroepithelium of the early mammalian telencephalon: a major site of neurogenesis. Proc. Natl Acad. Sci. USA 101 3196-3201 (2004).

47. Miyata, T. et al. Asymmetric production of surfacedividing and non-surface-dividing cortical progenito cells. Development 131, 3133-3145 (2004).

48. Englund, C. et al. Pax6, Tbr2, and Tbr1 are expressed sequentially by radial glia, intermediate progenitor cells, and postmitotic neurons in developing neocortex. J. Neurosci. 25, 247-251 (2005).

49. Sessa, A., Mao, C. A., Hadjantonakis, A. K., Klein W. H. \& Broccoli, V. Tbr2 directs conversion of radial glia into basal precursors and guides neuronal amplification by indirect neurogenesis in the developing neocortex. Neuron 60, 56-69 (2008).

50 Attardo, A Calegari, F Haubensak, W WilschBrauninger, M. \& Huttner, W. B. Live imaging at the onset of cortical neurogenesis reveals differential appearance of the neuronal phenotype in apical versus basal progenitor progeny. PLOS ONE 3, e2388 (2008).

51. Gaspard, N. et al. An intrinsic mechanism of corticogenesis from embryonic stem cells. Nature 455, 351-357 (2008)

52. Reynolds, B. A., Tetzlaff, W. $\&$ Weiss, S. A multipotent EGF-responsive striatal embryonic progenitor cell produces neurons and astrocytes. J. Neurosci. 12, 4565-4574 (1992).

53. Reynolds, B. A. \& Weiss, S. Generation of neurons and astrocytes from isolated cells of the adult mammalian central nervous system. Science 255, 1707-1710 (1992).
This landmark paper was the first to report culture conditions that allow the in vitro expansion (in a neurosphere system) of multipotent stem or progenitor cells present in the adult mammalian brain.

54. Laywell, E. D., Kukekov, V. G. \& Steindler, D. A Multipotent neurospheres can be derived from forebrain subependymal zone and spinal cord of adult mice after protracted postmortem intervals. Exp. Neurol. 156, 430-433 (1999).

55. Chojnacki, A. \& Weiss, S. Production of neurons, astrocytes and oligodendrocytes from mammalian CNS stem cells. Nature Protoc. 3, 935-940 (2008).

56. Ciccolini, F. Identification of two distinct types of multipotent neural precursors that appear sequentially during CNS development. Mol. Cell. Neurosci. 17, 895-907 (2001)

57. Ciccolini, F., Mandl, C., Holzl-Wenig, G., Kehlenbach, A. $\&$ Hellwig, A. Prospective isolation of late development multipotent precursors whose migration is promoted by EGFR. Dev. Biol. 284, 112-125 (2005).

58. Ciccolini, F. \& Svendsen, C. N. Fibroblast growth factor 2 (FGF-2) promotes acquisition of epidermal growth factor (EGF) responsiveness in mouse striatal precursor cells: identification of neural precursors responding to both EGF and FGF-2. J. Neurosci. 18 7869-7880 (1998)

59. Gritti, A., Cova, L., Parati, E. A., Galli, R. \& Vescovi, A. L. Basic fibroblast growth factor supports the proliferation of epidermal growth factor-generated neuronal precursor cells of the adult mouse CNS. Neurosci. Lett. 185, 151-154 (1995).

60. Gritti, A. et al. Multipotential stem cells from the adult mouse brain proliferate and self-renew in response to basic fibroblast growth factor. J. Neurosci. 16 1091-1100 (1996)

61. Louis, S. A. \& Reynolds, B. A. Generation and differentiation of neurospheres from murine embryonic day 14 central nervous system tissue. Methods Mol. Biol. 290, 265-280 (2005).

62. Martens, D. J., Tropepe, V. \& van Der Kooy, D. Separate proliferation kinetics of fibroblast growth factor-responsive and epidermal growth factor-responsive neural stem cells within the embryonic forebrain germinal zone. J. Neurosci. 20, 1085-1095 (2000).

63. Svendsen, C. N. et al. A new method for the rapid and long term growth of human neural precursor cells. J. Neurosci. Methods 85, 141-152 (1998)

64. Tropepe, V. et al. Distinct neural stem cells proliferate in response to EGF and FGF in the developing mouse telencephalon. Dev. Biol. 208, 166-188 (1999).

65. Uchida, N. et al. Direct isolation of human central nervous system stem cells. Proc. Natl Acad. Sci. USA 97, 14720-14725 (2000).

66. Singec, l. et al. Defining the actual sensitivity and specificity of the neurosphere assay in stem cell biology. Nature Methods 3, 801-806 (2006).

67. Doetsch, F., Petreanu, L., Caille, I., Garcia-Verdugo, J. M. \& Alvarez-Buylla, A. EGF converts transitamplifying neurogenic precursors in the adult brain into multipotent stem cells. Neuron 36, 1021-1034 (2002). This landmark study demonstrated that NSC identity could be acquired in vitro by a population of transit-amplifying precursors of the adult mammalian SVZ. These results suggested that exposure to growth factors can induce NSC exposure to growth factors can induce NSC
characteristics in populations that in vivo act transient neurogenic progenitors.

68. Gregg, C. \& Weiss, S. Generation of functional radial glial cells by embryonic and adult forebrain neural stem cells. J. Neurosci. 23, 11587-11601 (2003).

69. Golmohammadi, M. G. et al. Comparative analysis of the frequency and distribution of stem and progenito cells in the adult mouse brain. Stem Cells $\mathbf{2 6}$, 979-987 (2008).

70. Marshall, G. P., Reynolds, B. A. \& Laywell, E. D. Using the neurosphere assay to quantify neural stem cells in vivo. Curr. Pharm. Biotechnol. 8, 141-145 (2007).

71. Wachs, F. P. et al. High efficacy of clonal growth and expansion of adult neural stem cells. Lab. Invest. $\mathbf{8 3}$ 949-962 (2003).

72. Jessberger, S., Clemenson, G. D. \& Gage, F. H. Spontaneous fusion and nonclonal growth of adult neural stem cells. Stem Cells 25, 871-874 (2007).

73. Mori, H., Fujitani, T., Kanemura, Y., Kino-Oka, M. \& Taya, M. Observational examination of aggregation and migration during early phase of neurosphere culture of mouse neural stem cells. J. Biosci. Bioeng. 104, 231-234 (2007)

74. Campos, L. S. Neurospheres: insights into neural stem cell biology. J. Neurosci. Res. 78, 761-769 (2004).
75 Campos, L. S., Decker, L., Taylor, V. \& Skarnes, W. Notch, epidermal growth factor receptor, and $\beta 1$-integrin pathways are coordinated in neural stem cells. J. Biol. Chem. 281, 5300-5309 (2006).

76. Bez, A. et al. Neurosphere and neurosphere-forming cells: morphological and ultrastructural characterization. Brain Res. 993, 18-29 (2003).

77. Lobo, M. V. et al. Cellular characterization of epidermal growth factor-expanded free-floating neurospheres. J. Histochem. Cytochem. 51, 89-103 (2003).

78. Grandbarbe, L. et al. Delta-Notch signaling controls the generation of neurons/glia from neural stem cells in a stepwise process. Development 130, 1391-1402 (2003).

79. Weiss, S. et al. Multipotent CNS stem cells are present in the adult mammalian spinal cord and ventricular neuroaxis. J. Neurosci. 16, 7599-7609 (1996).

80. Johe, K. K., Hazel, T. G., Muller, T., Dugich-Djordjevic, M. M. \& McKay, R. D. Single factors direct the differentiation of stem cells from the fetal and adult central nervous system. Genes Dev. 10, 3129-3140 (1996).

81. Palmer, T. D., Takahashi, J. \& Gage, F. H. The adult rat hippocampus contains primordial neural stem cells. Mol. Cell. Neurosci. 8, 389-404 (1997)

82. Babu, H., Cheung, G., Kettenmann, H., Palmer, T. D. \& Kempermann, G. Enriched monolayer precursor cell cultures from micro-dissected adult mouse dentate gyrus yield functional granule cell-like neurons. PLoS ONE 2, e388 (2007).

83. Palmer, T. D. et al. Cell culture. Progenitor cells from human brain after death. Nature 411, 42-43 (2001).

84. Takahashi, J., Palmer, T. D. \& Gage, F. H. Retinoic acid and neurotrophins collaborate to regulate neurogenesis in adult-derived neural stem cell cultures. J. Neurobiol. 38, 65-81 (1999).

85. Pollard, S. M., Conti, L., Sun, Y., Goffredo, D. \& Smith, A Adherent neural stem (NS) cells from fetal and adult forebrain. Cereb. Cortex 16 (Suppl. 1), i112-i120 (2006).

86. Sun, Y. et al. Long-term tripotent differentiation capacity of human neural stem (NS) cells in adherent culture. Mol. Cell. Neurosci. 38, 245-258 (2008).

87. Spiliotopoulos, D. et al. An optimized experimental strategy for efficient conversion of embryonic stem (ES)-derived mouse neural stem (NS) cells into a nearly homogeneous mature neuronal population. Neurobio. Dis. 34, 320-331 (2009).

88. Goffredo, D. et al. Setting the conditions for efficient, robust and reproducible generation of functionally active neurons from adult subventricular zone-derived neural stem cells. Cell Death Differ. 15, 1847-1856 (2008).

89. Alexson, T. O., Hitoshi, S., Coles, B. L., Bernstein, A. \& van der Kooy, D. Notch signaling is required to maintain all neural stem cell populations--irrespective of spatial or temporal niche. Dev. Neurosci. $\mathbf{2 8}$ 34-48 (2006).

90. Coles-Takabe, B. L. et al. Don't look: growing clonal versus nonclonal neural stem cell colonies. Stem Cells 26, 2938-2944 (2008)

91. Cordey, M., Limacher, M., Kobel, S., Taylor, V. \& Lutolf, M. P. Enhancing the reliability and throughput of neurosphere culture on hydrogel microwell arrays Stem Cells 26, 2586-2594 (2008)

92. Louis, S. A. et al. Enumeration of neural stem and progenitor cells in the neural colony-forming cell assay. Stem Cells 26, 988-996 (2008).

93. Smith, A. G. Embryo-derived stem cells: of mice and men. Annu. Rev. Cell Dev. Biol. 17, 435-462 (2001).

94. Reynolds, B. A. \& Rietze, R. L. Neural stem cells and neurospheres--re-evaluating the relationship. Nature Methods 2, 333-336 (2005).

95. Dromard, C. et al. NG2 and Olig2 expression provides evidence for phenotypic deregulation of cultured central nervous system and peripheral nervous system neural precursor cells. Stem Cells 25, 340-353 (2007).

96. Copray, S. et al. Olig2 overexpression induces the in vitro differentiation of neural stem cells into mature oligodendrocytes. Stem Cells 24, 1001-1010 (2006).

97. Ligon, K. L. et al. Olig2-regulated lineage-restricted pathway controls replication competence in neural stem cells and malignant glioma. Neuron 53 503-517 (2007)

98. Molofsky, A. V. et al. Bmi-1 dependence distinguishes neural stem cell self-renewal from progenitor proliferation. Nature 425, 962-967 (2003). 
99. Chandran, S. et al. FGF-dependent generation of oligodendrocytes by a hedgehog-independent pathway. Development 130, 6599-6609 (2003).

100. Gabay, L., Lowell, S., Rubin, L. L. \& Anderson, D. J. Deregulation of dorsoventral patterning by FGF confers trilineage differentiation capacity on CNS stem cells in vitro. Neuron 40, 485-499 (2003). This study was one of the first to draw attention to the strong deregulation of the dorsoventral identity that FGF2 exerts on in vitro cultured NSCs.

101. Hack, M. A., Sugimori, M., Lundberg, C., Nakafuku, M. $\&$ Gotz, M. Regionalization and fate specification in neurospheres: the role of Olig2 and Pax6. Mol. Cell. Neurosci. 25, 664-678 (2004).

102. Kessaris, N., Jamen, F., Rubin, L. L. \& Richardson, W. D. Cooperation between sonic hedgehog and fibroblast growth factor/MAPK signalling pathways in neocortical precursors. Development 131 , 1289-1298 (2004).

103. Pollard, S. M., Wallbank, R., Tomlinson, S. Grotewold, L. \& Smith, A. Fibroblast growth factor induces a neural stem cell phenotype in foetal forebrain progenitors and during embryonic stem cell differentiation. Mol. Cell. Neurosci. 38, 393-403 (2008).

This manuscript described the rapid induction of several genes in neural cells following exposure to FGF2. The authors suggested that induction of these genes can be pivotal to imparting an NSC identity in in vitro cultured neural progenitors.

104. Carvajal-Gonzalez, J. M. et al. The dioxin receptor regulates the constitutive expression of the Vav3 proto-oncogene and modulates cell shape and adhesion. Mol. Biol. Cell 20, 1715-1727 (2009).

105. Fujikawa, K et al. Vav3 is regulated during the cell cycle and effects cell division. Proc. Natl Acad. Sci. USA 99, 4313-4318 (2002).

106. Bithell, A., Finch, S. E., Hornby, M. F. \& Williams, B. P. Fibroblast growth factor 2 maintains the neurogenic capacity of embryonic neural progenitor cells in vitro but changes their neuronal subtype specification. Stem Cells 26, 1565-1574 (2008).

107. Machon, O., Backman, M., Krauss, S. \& Kozmik, Z. The cellular fate of cortical progenitors is not maintained in neurosphere cultures. Mol. Cell. Neurosci. 30, 388-397 (2005)

108. Guillemot, F. Cell fate specification in the mammalian telencephalon. Prog. Neurobiol. 83, 37-52 (2007).

109. Heins, N. et al. Glial cells generate neurons: the role of the transcription factor Pax6. Nature Neurosci. 5, 308-315 (2002)

110. Calegari, F., Haubensak, W., Haffner, C. \& Huttner, $W$. B. Selective lengthening of the cell cycle in the neurogenic subpopulation of neural progenitor cells during mouse brain development. J. Neurosci. 25 6533-6538 (2005)

111. Pardal, R., Molofsky, A. V., He, S. \& Morrison, S. J. Stem cell self-renewal and cancer cell proliferation are regulated by common networks that balance the activation of proto-oncogenes and tumor suppressors. Cold Spring Harb. Symp. Quant. Biol. 70, 177-185 (2005).

112. Politis, P. K. et al. BM88/CEND1 coordinates cell cycle exit and differentiation of neuronal precursors. Proc. Natl Acad. Sci. USA 104, 17861-17866 (2007)

113. Politis, P. K., Thomaidou, D. \& Matsas, R. Coordination of cell cycle exit and differentiation of neuronal progenitors. Cell Cycle 7, 691-697 (2008).

114. Zheng, H. et al. p53 and Pten control neural and glioma stem/progenitor cell renewal and differentiation. Nature 455, 1129-1133 (2008).

115. Godlewski, J. et al. Targeting of the Bmi-1 oncogene/ stem cell renewal factor by microRNA-128 inhibits glioma proliferation and self-renewal. Cancer Res. $\mathbf{6 8}$, 9125-9130 (2008).

116. Molofsky, A. V., He, S., Bydon, M., Morrison, S. J. \& Pardal, R. Bmi-1 promotes neural stem cell self- renewal and neural development but not mouse growth and survival by repressing the p16Ink4a and p19Arf senescence pathways. Genes Dev. 19 1432-1437 (2005).

117. Molofsky, A. V. et al. Increasing p16INK4a expression decreases forebrain progenitors and neurogenesis during ageing. Nature 443, 448-452 (2006).

118. Kippin, T. E., Martens, D. J. \& van der Kooy, D. p21 loss compromises the relative quiescence of forebrain stem cell proliferation leading to exhaustion of their proliferation capacity. Genes Dev. 19, 756-767 (2005).

119. Beekman, C. et al. Evolutionarily conserved role of nucleostemin: controlling proliferation of stem/ progenitor cells during early vertebrate development. Mol. Cell. Biol. 26, 9291-9301 (2006).

120. Tsai, R. Y. \& McKay, R. D. A nucleolar mechanism controlling cell proliferation in stem cells and cancer cells. Genes Dev. 16, 2991-3003 (2002).

121. Kondo, T., Johnson, S. A., Yoder, M. C., Romand, R. \& Hashino, E. Sonic hedgehog and retinoic acid synergistically promote sensory fate specification from bone marrow-derived pluripotent stem cells. Proc. Natl Acad. Sci. USA 102, 4789-4794 (2005).

122. Kondo, T. \& Raff, M. Oligodendrocyte precursor cells reprogrammed to become multipotential CNS stem cells. Science 289, 1754-1757 (2000).

123. Kondo, T. \& Raff, M. Chromatin remodeling and histone modification in the conversion of oligodendrocyte precursors to neural stem cells. Genes Dev. 18, 2963-2972 (2004)

124. Alexanian, A. R. Epigenetic modifiers promote efficient generation of neural-like cells from bone marrowderived mesenchymal cells grown in neural environment. J. Cell. Biochem. 100, 362-371 (2007).

125. Alexanian, A. R., Maiman, D. J., Kurpad, S. N. \& Gennarelli, T. A. In vitro and in vivo characterization of neurally modified mesenchymal stem cells induced by epigenetic modifiers and neural stem cell environment. Stem Cells Dev. 17, 1123-1130 (2008).

126. Khoo, M. L., Shen, B., Tao, H. \& Ma, D. D. Long-term serial passage and neuronal differentiation capability of human bone marrow mesenchymal stem cells. Stem Cells Dev. 17, 883-896 (2008).

127. Toselli, M., Cerbai, E., Rossi, F. \& Cattaneo, E. Do amniotic fluid-derived stem cells differentiate into neurons in vitro? Nature Biotech. 26, 269-278 (2008)

128. Aoi, T. et al. Generation of pluripotent stem cells from adult mouse liver and stomach cells. Science 321 699-702 (2008)

129. Nishikawa, S., Goldstein, R. A. \& Nierras, C. R. The promise of human induced pluripotent stem cells for research and therapy. Nature Rev. Mol. Cell Biol. 9. 725-729 (2008).

130. Okita, K., Ichisaka, T. \& Yamanaka, S. Generation of germline-competent induced pluripotent stem cells. Nature 448, 313-317 (2007).

131. Takahashi, K et al. Induction of pluripotent stem cells from adult human fibroblasts by defined factors. Cell 131, 861-872 (2007).

132. Takahashi, K. \& Yamanaka, S. Induction of pluripotent stem cells from mouse embryonic and adult fibroblast cultures by defined factors. Cell 126, 663-676 (2006)

133. Huangfu, D. et al. Induction of pluripotent stem cells from primary human fibroblasts with only Oct4 and Sox2. Nature Biotech. 26, 1269-1275 (2008).

134. Lim, D. A. et al. Chromatin remodelling factor MIII is essential for neurogenesis from postnatal neural stem cells. Nature 458, 529-533 (2009).

135. Hsieh, J. \& Gage, F. H. Epigenetic control of neural stem cell fate. Curr. Opin. Genet. Dev. 14, 461-469 (2004).

136. Li, H. et al. Transcription factor MEF2C influences neural stem/progenitor cell differentiation and maturation in vivo. Proc. Natl Acad. Sci. USA 105, 9397-9402 (2008).

137. Dictus, C., Tronnier, V., Unterberg, A. \& Herold-Mende, C. Comparative analysis of in vitro conditions for rat adult neural progenitor cells. J. Neurosci. Methods 161, 250-258 (2007)

138. Gritti, A., Galli, R. \& Vescovi, A. L. Clonal analyses and cryopreservation of neural stem cell cultures. Methods Mol. Biol. 438, 173-184 (2008).

139. Akesson, E. et al. Long-term culture and neuronal survival after intraspinal transplantation of human spinal cord-derived neurospheres. Physiol. Behav. 92, 60-66 (2007)

140. Foroni, C. et al. Resilience to transformation and inherent genetic and functional stability of adult neural stem cells ex vivo. Cancer Res. 67, 3725-3733 (2007).

141. Morshead, C. M., Benveniste, P., Iscove, N. N. \& van der Kooy, D. Hematopoietic competence is a rare property of neural stem cells that may depend on genetic and epigenetic alterations. Nature Med. 8 268-273 (2002)

142. Smith, R., Bagga, V. \& Fricker-Gates, R. A. Embryonic neural progenitor cells: the effects of species, region, and culture conditions on long-term proliferation and neuronal differentiation. J. Hematother. Stem Cell Res. 12, 713-725 (2003)

143. Delaunay, D. et al. Early neuronal and glial fate restriction of embryonic neural stem cells. J. Neurosci. 28, 2551-2562 (2008)

144. Pinto, L. \& Gotz, M. Radial glial cell heterogeneity--the source of diverse progeny in the CNS. Prog. Neurobiol. 83, 2-23 (2007)

145. Evans, M. J. \& Kaufman, M. H. Establishment in culture of pluripotential cells from mouse embryos. Nature 292, 154-156 (1981)

146. Thomson, J. A. et al. Embryonic stem cell lines derived from human blastocysts. Science 282, 1145-1147 (1998).

147. Buehr, M. et al. Capture of authentic embryonic stem cells from rat blastocysts. Cell 135, 1287-1298 (2008).

148. Ying, Q. L., Nichols, J., Chambers, I. \& Smith, A. BMP induction of Id proteins suppresses differentiation and sustains embryonic stem cell self-renewal in collaboration with STAT3. Cell 115, 281-292 (2003).

\section{Acknowledgements}

We apologize to colleagues for the omission of papers that could not be cited owing to space constraints. We thank C. Consalez and members of the laboratory for critical reading of the manuscript. The work of the authors is supported by EuroSystem (FP7, European Union Health-F4-2008-200720), ESTools (FP6, European Union LSHG-CT-2006-018739), NeuroStemcell (FP7, European Union HEALTH-2008-B-222943), Progetto Piattaforma Cariplo Nobel (Fondazione Cariplo, Italy; 20052042/104878) to E.C. and Progetto di Ricerca di Interesse Nazionale (MIUR, Italy; \#20074MW29N) and Neuroscreen (FP6, European Union LSHB-CT-2007-037766) to L.C.

Competing interests statement

The authors declare no competing financial interests.

DATABASES

Entrez Gene: http://www.ncbi.nlm.nih.gov/gene ADAM12 $\mid$ BLBP $|\underline{C D 44}| \underline{C D H 20}|\underline{C D K N 1 A \mid C X 3 C L 1}| D A C H 1$ | FZD9 $|\underline{\text { GLAST }}| \underline{\text { HES } 5} \mid$ HEY1 $\mid$ KITLG | nucleostemin $\mid \underline{O L I G 1}$ PLZFIVAV3

UniProtKB: http://www.uniprot.or

BMI1 | FOXG1 | HB9 | Islet1 | Noggin | OTX2 | PAX6 | SOX1 |

FURTHER INFORMATION

Elena Cattaneo's homepage: http://www.cattaneolab.it

ALL LINKS ARE ACTIVE IN THE ONLINE PDF 
ERRATUM

Neural stem cell systems: physiological players or in vitro entities?

Luciano Conti and Elena Cattaneo

Nature Reviews Neuroscience 11, 176-187 (2010)

In Table 1 of the above article, the source of ESCs should be "Blastocyst" and the source of iPSCs should be "Fetal and adult tissues". 